\title{
Ultraweak Electromagnetic Wavelength Radiation as Biophotonic Signals to Regulate Life Processes
}

Hugo J. Niggli*

BioFoton AG, Rte. D‘Essert 27, CH-1733 Treyvaux, Switzerland

\begin{abstract}
In recent years the low level analysis of ultra-weak photon emission in human cells is achieved using sophisticated Photomultiplier Technique (PMT). The basis of photonic measurements goes back to the theoretical finding of Einstein that a photon, which hits a metal plate, causes an electrical impulse. This current can be detected by single photon detection device as mentioned before. As shown in a variety of analytical laboratories worldwide using this sensitive workhorse it is evident that all cells from plants over animals up to humans emit a low level biophotonic emission. The measured electromagnetic wavelengths of this miniscule 0.01 Femto Watt $\left(10^{-17} \mathrm{~W}\right)$ radiation are ranging from ultraviolet light over the visible up to the infrared region. In order to visualize the size of this very weak light source: the luminous power of a candle in a Lunar Distance (LD) (1 LD equal to $384 ' 400 \mathrm{~km}$ ) still can be measured using the photomultiplier system mentioned above. From biophotonics investigations so far, the origin of ultra-weak photon emission is the DNA as well as proteins coupled with radical reactions. In order to determine this radiation in human cells, a fibroblastic differentiation system was developed using dermal fibroblasts of skin. Since normal cells store efficiently ultra-weak photons, it has been shown that older cells as well as cancer tissue tend to lose this retention capacity. From all these results it seems evident, that this low level radiation serve as biophotonic signals in order to transfer information in biological systems. Further intense basic research is needed in order to show evidence that ultraweak electromagnetic radiation plays the key role in life.
\end{abstract}

Keywords: Biophotonic signals; Photomultiplier technique; Photon emission; Photon detection; Electromagnetic wavelengths; Radiation; Luminous power

\section{Introduction}

Photons participate in most atomic and molecular interactions and changes in life regulation processes. In this respect, the development of photomultiplier tubes (PMT's) in the early fifties of the last century was a key event in order to detect photons in biological tissue as reported by Colli et al. [1]. This practical discovery of light emission in cells by a highly sophisticated physical method was based on the theoretical finding of Einstein in 1905, the so-called photoelectric effect. For this breakthrough, Einstein received the Nobel Prize in Physics for the year 1921. The discovery of ultraweak photon emission by a physical device confirmed the so-called mitogenetic radiation determined by onion roots as biological detectors from the Russian biologist Alexander Gurwitsch as I reviewed 22 years ago [2]. The discovery measured latter on by PMT, that plant cells emit a low level radiation, was a coincidence. In the early nineteen fifties, PMT's were the breakthrough analytical technique in Physics, in order to detect single photons as side products of nuclear collisions. They allowed in the late fifties of the last century to provide evidence for the immense zoo of subatomic particles in modern physics. Colli as physical scientific researcher tried to test this new, highly sensitive device. At this time, Colli's wife bought some fresh vegetables on the street market and visited the physical laboratory of his husband, thereafter. She placed her shopping bag with the fresh bought plants in it, beside the new PMT. Shortly after this event, Colli checked his new device and realized an unexplained counting rate of the PMT. He concluded that the PMT was defect and returned it immediately to the factory in order to receive shortly after a new apparatus on guarantee. He tested then the substituted PMT again with fresh vegetables. To his surprise, the new, replaced PMT was again showing ultraweak photons (Emilio del Giudice, personal communication on Summer School 2010 in Neuss (Germany)). Therefore, Colli and his co-workers performed experiments with plant cells and published thereafter the observation of ultraweak photon emission in plants as mentioned above [1]. But it needed another twenty years, until Popp in Germany, Quickenden in Australia and Inaba in Japan confirmed in the middle 1970 s independently this ultraweak radiation in plant cells as measured already beginning of the 1950s in Italy [1,2]. In the meantime, it is now scientifically accepted that plants, animals and humans emit a weak, so called - biophotonic radiation which can be readily detected with an appropriate photomultiplier system $[3,4]$. Although the emission is extremely low in mammalian cells, it can be efficiently induced in human cell cultures by ultraviolet light as shown almost ten years ago [5]. This process is most probably coupled with a very weak delayed luminescence (DL). The scientific researchers, the physicist Fritz-Albert Popp and the biologist Yu Yan described this phenomenon twelve years ago as coherent states in biological tissues [6]. In the last years, we developed a cell culture model for biophotonic measurements using fibroblastic differentiation [7-15]. An in vivo application of ultraweak radiation on human skin was developed by Cohen and Popp [16] and most recently confirmed by Musumeci and co-workers [17]. Schrader et al. used this method in order to test antioxidant stress in vivo on human skin [18]. All these results open the highly interesting question if ultraweak photons serve as electromagnetic signals in biological systems in order to regulate life processes in plant, animal and human cells [19]. This review presented here, will show new insights on this highly interesting hypothesis and further, intense biophotonic research has to be undertaken, as initiated already by the German biophotonic research program [20] in order to show clear evidence of ultraweak photons as

*Corresponding author: Hugo J. Niggli, BioFoton AG, Rte. D‘Essert 27, CH-1733 Treyvaux, Switzerland, Tel: +410-79-267-16 15; E-mail:biofoton@hispeed.ch

Received February 21, 2014; Accepted April 17, 2014; Published April 27, 2014

Citation: Niggli HJ (2014) Ultraweak Electromagnetic Wavelength Radiation as Biophotonic Signals to Regulate Life Processes. J Electr Electron Syst 3: 126 doi:10.4172/2332-0796.1000126

Copyright: (c) 2014 Niggli HJ. This is an open-access article distributed under the terms of the Creative Commons Attribution License, which permits unrestricted use, distribution, and reproduction in any medium, provided the original author and source are credited. 
inducers of cellular activation processes shown for example more than 30 years ago in the rhodopsin protein molecule of the eye [21].

\section{Information Transfer by Electromagnetic Waves by Structured Water}

Rarely is it thought about the admirable achievement to transfer sound over large distances. Such a transmission is difficult because acoustic waves disappear quickly. Additionally their transfer of $343 \mathrm{~m} /$ sec in air at $20^{\circ} \mathrm{C}$ is slow compared to the velocity of electromagnetic waves. They propagate considerably faster with $299792458 \mathrm{~m} / \mathrm{sec}$. Clerk Maxwell predicted electromagnetic waves based on mathematical correlation of his Maxwell-equation as summarized elsewhere [19]. Heinrich Rudolf Hertz proofed the existence of such waves in the 1880s more than 130 years ago. In the year 1896 Guglielmo Marconi succeeded to transfer electromagnetic waves on short distances. Alexander Gurwitch, a brilliant biologist from Russia developed between 1920 and 1935 a biological hypothesis with mitotic onion roots in order to prove that light transfer information in cells [2,22]. In the early 1950s, Herbert Fröhlich confirmed theoretically the transfer of information by electromagnetic waves in biological systems as summarized recently by his last pupil Gérard Hyland [23]. The biophysicist Fritz-Albert Popp proposed together with the biologist Walter Nagl in the year 1983 an electromagnetic model of cell differentiation [24]. This was the first genius concept in biology of modern natural science based on ultraweak photon research that electromagnetic waves may be important in order to regulate life processes. In cellular systems, this low level radiation has been measured by a various of scientific researchers from Australia [25], Austria [26], Belgium [27], [Brazil [28-30], Czech Republic [3132], China [6,33-35], Germany [3,4,6,16,18-20,24,34-37], Great Britain [23,37-38], Holland [33,39-42], India [43,44], Italy [1,5,14-15,17,3334,45-47], Japan [48-54], New Zealand [25], Poland [55-57], Russia [22,58-62], South-Korea [63], Switzerland [2,5,11-15,19,45,64-68], Ukraine [69-71] and USA [72-76].

Water is structured energy. A typical example is a whirlpool showing excessive power. As reported by Wernet et al. [77] in the year 2004, triangular chains, 3-dimensional rings and even triangulary pyramids are found in the molecular arrangement of water. The nuclear physicist Emilio del Giudice from Milan (Italy) found coherent regions in water [78]. Light is composed normally from photons of different wavelengths compared to the colours of a rainbow. As del Giudice emphasizes, coherent photons are very likely to a single, intense colour. According to his research, water is able to pick up information of other molecules similar to a DVD writer and player. This is even possible if the originated molecule is disappeared. This important observation is further corroborated by the Japanese physicist Kunio Yasue and his colleagues [79]. They found that water molecules are capable to transform disordered energy in coherent photons, a process called supra-radiation according to the physicist Dicke [80]. In summary, water, the natural medium of all cells, is most probably the crucial controller of the transmission of information from cellular molecules as DNA and proteins. Water molecules may perform this process through arrangement of highly organized patterns, as proposed by Wernet and co-workers mentioned above, which then can memorize wave frequencies. $70 \%$ of the human cell is not else than structured water. In the brain the amount is elevated to $90 \%$. Only blood (92\%) and saliva $(98 \%)$ contain more water. Most interestingly the high level of water in the brain decreases with age. The American biochemist Albert-Szent Györgyi, originated from Hungary, received in 1937 the Nobel Prize for Medicine. He claimed that water is the mother for vital processes in the cell [81].

\section{DNA Damage and Repair: Photochemical Processes in Order to Induce Intercellular Communication by Electromagnetic Waves}

We have 15 years ago shown that in vivo induction of pyrimidine dimers in human skin by UVA radiation is not only a sign of DNA damage, but may initiate intercellular communication [12]. As reviewed most recently [19], DNA changes are mostly induced by interaction of UV radiation with molecules of biological significance. Absorption of UV-light by nucleic acids are inducing the most fatal effects in cells. As summarized by Niggli [82], pyrimidine photodimers are the major photoproducts induced by UV light with crucial biological effects. It was James Cleaver in San Franciso in the year 1968 [83] who found the cause of skin cancer after intensive exposure to the sun in humans with the illness Xeroderma Pigmentosum. Missing DNA excision repair was the biochemical reason for high levels of skin cancer in young people suffering on this well investigated genetic disease. Beside enzymatic cutting of photoinduced DNA changes, in order to regain hereditary stability of the damaged genome induced by UV-light, the photo repair system as studied by Richard Setlow and William Carrier in the year 1964 [84], is another highly relevant repair process of UV damaged DNA. Also a highly important molecule of life is oxygen. A few minutes without oxygen may lead to the fatal event of death. Most interestingly, nerve tissue and cells of the brain, composed of only to $2 \%$ of the body weight; consume more than $20 \%$ of the oxygen taken by breath. The Russian chemist Vladimir Voeikov established the hypothesis that the photons stored in oxygen gain access to the cells by radical reactions [85]. Radicals are chemically, highly active substances [86]. They arise in plant, animal or human cells by irradiation with ultraviolet light or ionizing electromagnetic waves like X-rays. Vitamin $\mathrm{E}$ and superoxide dismutase, for example, influence significantly radical reaction processes which happen in aqueous solutions. According to Voeikov radical processes are indispensable to life in order to gain the stored light energy in oxygen. Together with Emilio del Giudice he showed that water respiration is the basis of the living state [87]. As mentioned above, the Italian physicist Del Giudice showed that excited atoms and molecules are interacting with the zero point vacuum fields as summarized by Lynne Mc Taggart [88]. In these processes arise small areal units of high order state. These so-called Coherent Domains (CD) have in water a diameter of about $100 \mathrm{~nm}$ fitting to about $10^{7}$ water molecules. The lifespan of these coherent domains is estimated to months or even long-lasting periods over years. A CD is surrounded by normal water, so-called bulk water. As summarized by Voeikov and Del Giudice [87] water hydrating hydrophilic surface areas is significantly different from bulk water. These diversities in density, freezing temperature, viscosity and relative permittivity are so striking that Zheng and co-workers [89] considered it as a fourth aggregate state. They reported that the thickness of this layer is probably hundreds of microns. Pollack [90] defined water adjacent to hydrophilic surfaces as so-called "Exclusion Zone Water" (EZ-water). As outlined by Voeikov and Del Giudice [87] the most important features of EZ-water is the prominent peak of light absorption in the UVC range of $270 \mathrm{~nm}$. Most interestingly EZ-water excited by this wavelength emits low level photon emission. In addition, the thickness of the EZ-water layer increases with illumination by visible light. IR radiation enhances the size of EZ-water significantly stronger, confirming the results by Albrecht-Buehler showing IR radiation effects in cells $[73,75]$. Based on these above-mentioned qualities, Voeikov and Del Giudice conclude that EZ-water can store energy. Their most important conclusion is that a CD in water is able to transform low grade energy with high entropy in high grade energy with low entropy. In this process oxygen is needed, in short: Cells, which contain at least $70 \% \mathrm{H}_{2} 0$, perform water respiration. 
Patrick and Rahn [91] investigated in the seventies of the last century the yield of thymine dimerization upon UVB-irradiation in DNA as a function of photosensitizers in the presence and absence of oxygen. They observed that that the pyrimidine dimer yields are about three- to six fold lower in the presence of oxygen confirming the report of Greenstock et al. [92] of reduced dimer yields of UV-Irradiated thymine solution. These quenching results from the transfer of the excitation from the sensitizer to the oxygen. This reaction is very fast and accounts for almost all quenching of triplets to oxygen as reviewed by Foote in the year 1976 [93]. I have shown in the year 1983 [82], that after UVC and UVB irradiation superoxide dismutase in the irradiation medium of the UV exposed cells enhance the pyrimidine dimer yield for both UV ranges by $25 \%$, while catalase lower the dimerization in the size of $15 \%$. It was discussed in this doctoral thesis [82], that the decrease in dimer yields observed in fibroblasts treated with the enzyme catalase is probably due to the quenching of molecules in excited states by the catalase produced molecular oxygen which is confirming the report of Patrick and Rahn [91]. Surprisingly, superoxide dismutase which is producing during its catalytic reaction oxygen too, shows higher dimer yields. It is well known that the uncatalyzed reaction is producing singlet oxygen [94]. These authors also show, that superoxide dismutase suppresses singlet oxygen production which has been shown to be involved in cell damage and carcinogenesis [86]. A report of Goda et al. [95] demonstrates that in the catalytic reaction the resultant $\mathrm{O}_{2}$ is formed in the triplet state in contrast to the non-enzymatic reaction. The difference may be accounted for by the presence of catalytically active $\mathrm{Cu}^{2+}$ ions in the dismutase molecule [96]. However, triplet oxygen may be capable to introduce pyrimidine dimers. In this respect we have also shown that UVA radiation which produces pyrimidine photodimers mostly via photosensitization [97] are introduced on human skin in vivo [12] as detected by antibody staining of dimers. Lamola has shown chemical induction of dimers in the dark [98]. In this respect, Giuseppe Cilento has created a photobiochemistry without light as reviewed in the year 1988 [29]. As Voeikov and Del Giudice emphasize, it has now become clear that life is possible without sunlight [87]. Fantastic ecosystems have been found at the bottom of the ocean. There is no light and no oxygen from the atmosphere at 10 kilometer below the ocean surface. The temperature is rarely more than $2-4^{\circ} \mathrm{C}$. Most surprisingly, highly active aerobic animals of various, different species, live in this cold darkness. It is possible that they use as energy source the thermal heat emerging from the hot, inner core of our Earth. It is well know from marine research that the basic physiology and biochemistry of these living beings in the cold darkness of the deep ocean is not significant different from those animals living on the land under the sun. The continuous flow of energy in their bodies required for multiplication, growth and life formation is preserved by their efficient capacity to utilize energy from their scanty surrounding area. But it has to be noted that this ability is not the specific property of deep-sea creatures. It is the general strategy of all life. Another astonishing example of light in the cells is the desert mice Monodelphis domestica. As Ley published almost 30 years ago, these animals mostly living in the dark have an efficient DNA repair system based on photo reactivation [99]. As Lynne Mc Taggert reviewed [88], Popp found in 1975 that carcinogens absorb ultraviolet-A light (UVA) in the range of $380 \mathrm{~nm}$. He tested first benzo[a]pyrene by irradiation in the UVA range and found that this carcinogen, causing for example scrotal cancer in chimney sweepers, absorb the UV radiation and re-emit then photons at a complete different frequency. Most surprisingly, the harmless benzo[e]pyrene allowed the UV-light to pass through it unchanged. Popp was astonished by this observation and performed his test on 37 different chemicals. Several tested substances are cancer causing, others in this testing system are unoffending chemicals. Using his test he was able to predict the carcinogenic potential of his tested substance as reviewed in the year 1979 [100]. In the meantime it is clear that the carcinogenic substances predicted by the UVA-test of Popp can interchelate with the hereditary DNA source. Benzo[a]pyrene for example is a so-called procarcinogen which is activated by detoxification enzymes like cytochromes $\mathrm{P} 450$ in the mitochondria to the highly carcinogenic Benzo[a]pyrene-7,8-dihydrodiol-9,10-epoxide interchelating with the guanine residue of the DNA [86]. This activation process is similar to that of aflatoxin $\mathrm{B}_{1}$ found for example in Aspergillus flavus and Aspergillus parascitus. Aspergillus flavus show accelerated growth in decomposed peanuts, but also in rotten hay or grains in a decay action. The epoxide is here induced by the cytochrome $\mathrm{P} 450$ pathway in hepatocytes. Most interestingly for this enzymatic processes water and oxygen is needed. As pyrimidine dimers, these highly toxic chemicals change the DNA source and may induce mutations, leading finally to carcinogenesis $[82,86]$. We have in the year 1999 reported that in vivo induction of pyrimidine dimers in human skin by UVA radiation is not only initiation of cell damage, but may be a common biochemical pathway of intercellular communication [12]. As reviewed elsewhere $[19,66]$, ultra weak photon emission is most probably involved in this communication process. It is well known, that biophotonic emission has been detected both in the ultraviolet as well as in the visible region of the electromagnetic spectrum $[2,19]$. There is substantial evidence that DNA is an important source of ultra-weak photon emission $[2,11,19,50,66]$. As published more than 20 years ago, normal fibroblasts tend to store UV-light efficiently, while excision repair deficient Xeroderma Pigmentosum cells [83] loose the capacity to store ultraweak photons. This observation was confirmed then years ago in report showing temperature dependence of ultraweak photon emission in fibroblastic differentiation after artificial UV-exposure $[101,102]$. In several reports $[12,66,102]$, we have proposed that pyrimidine dimers are inducers of photonic activation of biochemical pathways via excision repair of pyrimidine photodimers in DNA similar to the more than forty years ago published light-driven activation process of chemical reactions by bacteriorhodopsin [103]. As reported by Albrecht-Buehler [73,75], cells use infrared radiation in order to perform intercellular communication. In this respect, it is of high interest to observe that EZ-water emit in the UVC region as reported by Voeikov and Del Giudice recently [87]. Theoretical consideration of Fröhlich, propose intercellular communication by coherent states of cells. As discussed by John Swain [72], there are at least two types of quantum electromagnetic communication systems associated with the living state. One is in the microwave frequency range as hypothesized by Fröhlich [23], the other is from the UV, over the visible to the infrared region: UV and visible is suggested by Popp $[3,4,34,58]$, the infrared data is based on the scientific observations of Albrecht Buehler $[73,75]$. According to Swain [72] there exists a coupling by resonance between these two regions. As Swain [72] emphasizes, a biological system can easily store low microwave energy and transfer it to high energy photons as found in IR, visible and UV regions. In John Swain's view [72], there exists, as cited, "a natural framework not just for a biological molecule to experience long-range forces pulling it to where it should go, but also for the appropriate amount of energy to be transferred between them. The use of single photons as part of cell-tocell signaling is also fascinating and the sort of system here could allow for a high degree of selectivity with little cross-talk by choosing slightly different optical frequencies for different communication". Based on Fröhlich's hypothesis of quantum, coherent behavior in cells, microtubules as light conductor are important as proposed 25 years ago by the scientist Bornens from Belgium [27]. In this concept, structured 
Citation: Niggli HJ (2014) Ultraweak Electromagnetic Wavelength Radiation as Biophotonic Signals to Regulate Life Processes. J Electr Electron Syst 3: 126. doi:10.4172/2332-0796.1000126

water and their respiration processes, as brilliant implicated by Voeikov and Del Giudice, play an highly important role as infinite energy source in the dark [87]. Further intense, bio photonic research has to be realized in order to show further evidence, that the electromagnetic waves are the essential key in intra- and intercellular communication processes.

\section{Acknowledgements}

would like to thank Professor Lee Ann Laurent-Applegate (CHUV, Lausanne, Switzerland) as well as Dr. Max Bracher (BioFoton AG, Treyvaux, Switzerland) for critical reading of the manuscript and many helpful discussions. This work is dedicated to Emilio Del Giudice who died on the 31'st of January 2014. He is the Italian pioneer of ultraweak photonic research. He ingeniously introduced the basis of quantum physics into high sophisticated, modern cell research.

\section{References}

1. Colli L, Facchini U, Guidotti G, Dugnani Lonati R, Arsenigo, M et al. (1955) Further measurements on the bioluminescence of the seedlings. Experientia 11: $479-481$.

2. Niggli HJ (1992) Ultraweak photons emitted by cells: biophotons J Photochem Photobiol B: Biol 14: 144-146.

3. Popp FA, Li KH, Gu Q (1992) Recent Advances in Biophoton Research and its Application, World Scientific, Singapore.

4. Chang JJ, Fisch J, Popp FA (1998) Biophotons Kluwer Academic Publishers Dordrecht, Netherlands, Europe.

5. Niggli HJ, Tudisco S, Privitera G, Applegate LA, Scordino A, et al. (2005) LaserUltraviolet-A induced ultraweak photon emission in mammalian cells. J Biomed Opt 10: 024006.

6. Popp FA, Yan Y (2002) Delayed luminescence of biological systems in terms of coherent states. Physics letters A 290-293.

7. Bayreuther K, Rodemann HP, Hommel R, Dittman K, Albiez M, et al. (1988) Human skin fibroblasts in vitro differentiate along a terminal cell lineage, Proc natl Acad Sci USA 85: 5112-1516.

8. Niggli HJ, Francz PI (1992) May ultraviolet light-induced ornithine decarboxylase response in mitotic and postmitotic human skin fibroblasts serve as a marker of aging and differentiation? Age 15: 55-60

9. Niggli HJ (1993) Aphidicolin inhibits excision repair of UV-induced pyrimidine photodimers in low serum cultures of mitotic and mitomycin C-induced postmitotic human skin fibroblasts. Mut Res 295: 125-133.

10. Niggli HJ , Applegate LA (1997) Glutathione response after UVA irradiation in mitotic and postmitotic human skin fibroblasts and keratinocytes. Photochem Photobiol 65: 680-684

11. Niggli HJ (1996) the cell nucleus of cultured melanoma cells as a source of ultraweak photon emission. Naturwissenschaften 83: 41-44.

12. Applegate LA, Scaletta C, Panizzon R, Niggli HJ, Frenk E (1999) In vivo induction of pyrimidine dimers in human skin by UVA radiation: Initiation of cell damage and/or intercellular communication? Int J of Mol Med 3: 467-472.

13. Niggli HJ, Scaletta C, Yu Y, Popp FA, Applegate LA (2001) Ultraweak photon emission in assessing bone growth factor efficiency using fibroblastic differentiation. J Photochem Photobiol B: Biol. 64: 62-68.

14. Niggli HJ, Tudisco S, Privitera G, Applegate LA, Scordino A, et al. (2005) Laserultraviolet-A-induced biophotonic emission in cultured mammalian cells. In: Biophotonics: Optical Science and Engineering for the $21^{\text {st }}$ century (X. Shen and R. Van Wijk,edn.) Springer New York USA

15. Niggli HJ, Tudisco S, Lanzanò L, Applegate LA, Scordino A, et al. (2008) Laser-ultraviolet-A-induced ultraweak photon emission in human skin cells: $A$ biophotonic comparision between keratinocytes and fibroblasts. J Exp Biol 46: 358-363.

16. Cohen S, Popp FA (1997) Biophoton emission of the human body, J Photochem Photobiol B: Biology 40: 187-189.

17. Musumeci $F$ (2007)Spectral analysis of photoinduced delayed luminescence from human skin in vivo. Conference Paper of European Conference on Biomedical Optics. Munich, Germany.

18. Jain, Rieger I, Rohr M, Schrader A (2010), Antioxidant efficiency on human skin in vivo, Skin Pharmacol Physiol 23: 266-272.
19. Niggli HJ (2014) Biophotons: Ultraweak light impulses regulate life processes in aging Journal of Gerontology \& Geriatric Research in Press.

20. Liedtke S, Popp J, Laser, Licht und Leben (2006) Visions for better Health Care WILEY-VCH Verlag GmbH\&Co. KGaA, Weinheim, Germany.

21. Stryer $L$ (1987) the molecule of visual excitation. Scientific American 257: 42 50 .

22. Beloussov L (1997) Life of Alexander G. Gurwitsch and his relevant contribution to the theory of morphogenetic fields. Int Dev Biol 41: 771-779.

23. Hyland GJ (2009) Fröhlich's physical theory of cancer- Fröhlich's path from theoretical physics to biology and the cancer problem. Neural Network World 19: $337-354$

24. Nagl W, Popp FA (1983) A physical (electromagnetic) model of differentiation: basic considerations, Cytobios 37: 45-62.

25. Tilbury RN, Quickenden TI (1987) The effect of cosmic-ray shielding on the ultraweak bioluminescence emitted by cultures of Escherichia Coli. Radiat Res 112: 398-402.

26. Schwabl H, Klima H (2005) Spontaneous ultraweak photon emission from biological systems and the endgenous light field. Forsch Komplementermed Klass Naturheilkunde 12: 84-89.

27. Bornens M (1979) The centriole as a gyroscopic oscillator. Implications fo cellorganization and some other consequences. Biologie Cellulaire 35: 115 132

28. Cilento G (1984) Generation of electronically excited triplet species in biochemical systems. Pure Appl Chem 56: 1179-1190.

29. Cilento G (1988) Photochemistry without light. Experientia 44: 572-576.

30. Gallep CM, Moraes TA, Santos SRD, Barlow PW (2013) Coincidence of biophoton emission by wheat seedlings during simultaneous. Transcontinental germination tests Protoplasma 250: 793-796.

31. Cifra M, Fields JM, Farhadi A (2011) Electromagnetic cellular interactions Progress in Bioph Mol Bio 105: 223-246.

32. Pokorny J, Vedruccio C, Cifra M, Kucera O (2011) Cancer physics, diagnostics based on damped cellular elastoelectrical vibrations in microtubules. Eur Biophys J 40: 747-759

33. Shen X, Wijk RV (2005) Biophotonics, Springer Science Buisness media. New York, USA.

34. Chang JJ, Fisch J, Popp FA (1998) Biophotons, Kluwer Academic Publisher Dordrecht, Netherland.

35. Popp FA, Chang JJ, Herzog A, Yan Z, Yan Y (2002) Evidence of non-classical (squeezed) light in biological sysems, Phys Lett A 293: 98-102.

36. Rattemeyer M, Popp FA, Nagl W (1981) Evidence of photon emission from DNA in living systems, Naturwissenschaften.68: 572-573.

37. Ho MW, Popp FA, Warnke U (1994) Bioelectrodynamics and Biocommunication World Scientific Singapore.

38. Ho MW (1995) Bioenergetics and the coherence of organisms. Neuronetwork World 5: 733-750.

39. Hyland GJ (2000) Physics and biology of mobile telephony. Lancet 356: 1833 1836.

40. Wijk EV, Kobayashi M, Wijk RV, Greef JV (2013) Imaging of ultra-weak photon emission in mammalian cells. PLos One 8: e84579.

41. Wijk RV, van Aken JM (1992) Photon emission in tumor biology. Experientia 48: 1092-1102.

42. Wijk RV, Aken HV. (1991) Spontaneous and light-induced photon emission by rat and by hepatoma cells. Cell Biophys. 18: 15-29.

43. Bajpai RP (2003) Symposium in Print on Biophoton, National Institute of Science Communication and Information Resources, CSIR, New Delhi, India, Indian J Exp Biol 41: 5.

44. Bajpai RP (2008) Biophotons and Alternative Therapies, National Institute of Science Communication and Information Resources, CSIR, New Delhi (India) Indian Journal of Exp. Biol. 46: 5

45. Scordino, Baran I, Gulino M, Ganea C, Grasso R, et al. (2014) Ultra-weak delayed luminescence in cancer research: a review of the results by the ARETUSA equipment submitted. 
Citation: Niggli HJ (2014) Ultraweak Electromagnetic Wavelength Radiation as Biophotonic Signals to Regulate Life Processes. J Electr Electron Syst 3: 126. doi:10.4172/2332-0796.1000126

Page 5 of 6

46. Giudice ED, Elia V, Tedeschi A (2009) Role of water in the living organism. Neural Network World 19: 355-360.

47. Giudice ED, Preparata G, Vitello G (1988) Water as a free electric dipole laser Phys Rev Lett 61: 1085-1088.

48. Inaba H (1988) Super-high sensitivity systems for detection and analysis of ultraweak photon emission from biological cells and tissues. Experientia 44 550-559.

49. Scott RQ, Mashiko S, Kobayashi M, Hishinuma K, Ichimura T (1989) Twodimensional detection of ultraweak bioluminescence using a single-photon image acquisition system, J Opt Soc AM 4: 183-185

50. Devaraj B, Scott RQ, Roschger P, Inaba H (1991) Ultraweak photon emission from rat liver nuclei. Photochem. Photobiol. 54: 289-293.

51. Nakamura K, Hiramatsu M (2005) Ultra-weak photon emission from human hand: Influence of temperature and oxygen concentration on emission. Photochem Photobiol B. Bio 80: 156-160.

52. Ichimura T, Hiramatsu M, Hirai N, Hayakawa T (1989) Two-dimensional imaging of ultra-weak emission from intact soybean roots. Photochem. Photobiol 50 283-286.

53. Makino T, Kato K, lyozumi H, Honzawa H, Tachiiri Y (1996) Ultra-weak luminescence generated by sweet potato and fusarium oxysporum interactions associated with a defense response. Photochem. Photobiol 64: 953-956.

54. Inaba H, Shimizu Y, Tsuji Y, Yamagishi A (1979) Photon counting spectra analyzing system of extraweak chemi and bioluminescence for biochemical applications. Photochem Photobiol 30: 169-175.

55. Slawinska D, Slawinski J (1983) Biological chemiluminescence. Photochem Photobiol 37: 709-715.

56. Chwirot WB, Dygdala RS, Chwirot S (1986) Quasimonochromatic-light-induced photon emissionfrom microsporocytes of larch showing oscillations decay behavior predicted by an electromagnetic model of differentiation. Cytobios 47 $137-146$

57. Chwirot WB (1988) Ultraweak photon emission and anther meiotic cycle in laryx europea. Experientia 44: 594-599.

58. Popp FA, Beloussov LV (2003) Integrative Biophysics: Biophotons, Kluwer Academic Publishers Boston,USA.

59. Voeikov V (2001) Reactive oxygen species, water, photons and life, Riv Biol Biol Forum 94: 237-258.

60. Gurwitsch AG (1947) Une théorie du champ biologique cellulaire. Bibliotheca Biotheoretica Series D.V. Leiden, Netherland.

61. Popov GA, Tarusow BN (1963) Nature of spontaneous luminescence of animal tissues. Biofizika 8: 317-320.

62. Beloussov LV, Voeikov VL, Martynyuk VS (2007) Biophotonics and Coherent Systems in Biology, Springer Science-Buisness Media New York, USA.

63. Choi C, Woo WM, Lee MB, Yang JS, Soh KS, et al. (2002) Biophoton emission from the hands, J Korean Phys Soc 41: 275-278.

64. Bischof M (1995) Biophotonen das Licht in unseren Zellen, Verlag Zweitausend und Eins Leipzig. Deutschland.

65. Niggli HJ (1998) Biophotons: Our body produces light. Network 65: 16-17.

66. Niggli HJ, Scaletta C, Yan Y, Popp FA, Applegate LA (2001) UV-induced DNA damage and ultraweak photon emission in human fibroblastic skin cells: parameters to trigger intra- and extra-cellular photobiostimulation, Trends in Photochem Photobiol 8: 53-65.

67. Fels D (2009) Cellular communication through light. PLoS One 4: E5086.

68. Weilenmann U (2010) Mögliche wissenschaftliche Ansätze als Erklärungsgrundlage komplementärmedizinischer Therapien, Swiss J Integrative Med 22: 171-178.

69. Brizhik L, Musumeci F, Scordino A, Trigla A (2000) The soliton mechanism of the delayed luminescence of biological systems. Europhys Lett $52: 238$

70. Brizhik L, Scordino A, Trigla A, Musumeci F (2001) Delayed luminescence of biological systems arising from correlated many soliton-states. Phys Rev 64 031902.

71. Brizhik L (2003) Dynamical properties of Davydov solitons. Ukr J Phys 48 : 611-622
72. Swain $\mathrm{J}$, on the possibility of large upconversions and mde coupling between Fröhlich states and visible photons in biological systems

73. Albrecht-Buehler G (1992) Rudimentary form of cellular vision. Proc Natl Acad Sci USA 89: 8288-8292.

74. Eller MS, Yaar M, Gilchrest BA (1994) DNA damage and melanogenesis Nature 372: 413

75. Albrecht-Buehler G (2000) Reversible excitation light-induced enhancement of fluorescence of live mammalian mitochondria. FASEBJ 14: 1864-1866.

76. Swain J (2006) on the possibility of large upconversions and mode coupling between Fröhlich states and visible photons in biological systems.

77. Wernet P, Nordlund D, Bergmann U, Cavalleri M, Odelius M, et al. (2004) The structure of the first coordination shell in liquid water. Science 304: 995-999.

78. Giudice ED, Preparata G (1988) Water as a free electric dipole laser. Phys Rev Lett 61: 1085-1088.

79. Jibu M, Yasue K, Hagan S (1997) Evanescent (tunneling) photon and cellular vision. Bio systems 42: 65-73.

80. Dicke RH (1954) Coherence in spontaneous radiation processes. Phys Rev 93: 99-110.

81. Szent-Györgyi A (1937) Oxidation, energy transfer and vitamins Nobel Prize Lecture of December $11^{\text {th }}$.

82. Niggli H (1983) Formation and excision of cyclobutane-type pyrimidine dimers in human skin fibroblasts after irradiation with ultraviolet light. Doctoral thesis in Sciences ,University of Lausanne,Switzerland 22:1390-1395.

83. Cleaver JE (1968) Defective repair replication of DNA in xenoderma pigmentosum. Nature, London, 218: 652-656.

84. Setlow R RB, Carrier WL (1964) The disappearance of thymine dimers from DNA: an erro-correcting mechanism. Proc Natl Acad Sci USA, 51: 226-231.

85. Voeikov VL (2005) Biophotonic analysis of spontaneous self-organizing oxidative processes in aqueous systems, In: Biophotonics: Optical Science and engineering for the $21^{\text {st }}$ Century, Springer Verlag ,New York, Xun Shen and Roeland Van Wijk, edn. 141-145.

86. Cerutti PA (1985) Prooxidant states and promotion Science. 227: 375-381.

87. Voeikov VL, Giudice ED (2009) Water respiration - The basis of the living state. Water 1: 52-75.

88. Mc Taggert L (2003) The Field: The Quest for the Secret Force of the Universe Harper Collins Publisher, New York.

89. Zheng JM, Chin WC, Khijniak E, Jr Khijniak E, Pollack GH (2006) Surfaces and interfacial water: evidence that hydrophilic surfaces have long-range impact. Adv Colloid Sci 23: 19-27.

90. Pollack GH (2001) Cells, Gels and Engines of Life. Ebner and Sons, Seattle

91. Patrick MH, Rahn RO (1976) Photochemistry and Photobiology of Nucleic Acids. Academic Press, New York, 35-95.

92. Greenstock CL, Brown IH, Hunt JW, Johns HE (1967) Photodimerization of pyrimdine nucleic acid derivatives in aqueous solution and the effect of oxygen. Biochem Biophys Res Commun 27: 431-436.

93. Foote CS (1976) Photosensitized Oxidation and Singlet Oxygen: Consequences in Biological Systems. Free radicals in Biology II Academic Press, New York 2: $85-133$

94. Mayeda EA, Bard AJ (1974) Singlet oxygen. Suppression of its production in dismutation of superoxide ion by superoxide dismutase. J A ChemSoc 96 : 4023-4024.

95. Goda K, Kimura T, Thayer AL, Kees K, Schaap AP (1974) Singlet molecula oxygen in biological systems: Non quenching of singlet oxygen-mediated chemiluminescence by superoxide dismutase. Biochem Biophys Res Commun 58: 660-666.

96. Agro F, Rinaldi A, Floris G, Rotilio G (1984) A free-radical intermediate in the reduction of plant Cu-amine oxidase. FEBS Lett 176: 378-380.

97. Rochette PJ, Therrien JP, Drouin R, Perdiz D, Bastien N, et al. (2003) UVA induced cyclobutane pyrimidine dimers form predominantly at thymine-thymine dipyrimidines and correlate with the mutation spectrum in rodent cells. Nucleic Acids Res 31: 2786-2794. 
Citation: Niggli HJ (2014) Ultraweak Electromagnetic Wavelength Radiation as Biophotonic Signals to Regulate Life Processes. J Electr Electron Syst 3: 126 . doi:10.4172/2332-0796.1000126

Page 6 of 6

98. Lamola AA (1968) Excited state precursors of thymine photodimers. Photochem Photobiol 7: 619-632

99. Ley RD (1985) Photo reactivation of UV-induced pyrimidine dimers and erythema in the marsupial Monodelphis domestica. Proc Natl Acad Sci USA 82: $2409-2411$.

100.Popp FA, Becker G, König HL, Peschka W (1979) Electromagnetic BioInformation Urban \& Schwarzenberg. Baltimore.
101.Niggli HJ (1993) artificial sunlight irradiation induces ultraweak photon emission in human skin fibrolbasts. J Photochem Photobiol B: Biol 18: $281-$ 285.

102. Niggli HJ (2003) Temperature dependence of ultra-weak photon emission in fibroblastic differentiation after irradiation with artificial sunlight. Indian J Exp Bio 41: 419-423.

103. Oesterhelt D, Stoeckenius W (1971) Rhodopsin-like protein from the purple membrane of Halo bacterium halobium. Nature,London 233: 149-152. 